\title{
Lower BCL11B expression is associated with adverse clinical outcome for patients with myelodysplastic syndrome
}

Xin Huang ${ }^{1+} \mathbb{D}$, Cunte Chen $^{2 \dagger} \mathbb{B}$, Mengjun Zhong ${ }^{2+} \mathbb{D}$, Suxia Geng ${ }^{1} \mathbb{D}$, Yujie Zhao ${ }^{2} \mathbb{D}$, Minming Li ${ }^{1}$, Chenxin Deng ${ }^{1}$,



\begin{abstract}
Myelodysplastic syndrome (MDS) is an aggressive and genetically heterogeneous disease with poor prognosis. Cellular immune disorder is a common characteristic of this disease and is thought to be related to clinical outcome. Alterations in T cell clonal expansion and T cell dysfunction has been detected in MDS patients. Little is known about whether there are immune biomarkers to evaluate the T cell alterations with clinical outcome. Previous studies have demonstrated that B-cell leukemia/lymphoma 11B (BCL11B) plays an important role in regulating $T$ cell development and proliferation. In this study, the prognostic value of BCL11B for MDS patients was explored by analyzing RNA-seq data from 270 patients in two datasets in the Gene Expression Omnibus (GEO) database and real-time quantitative PCR data (qRT-PCR) of 31 bone marrow (BM) samples of MDS and 6 BM samples of patients with MDS progress to secondary acute myeloid leukemia (SAML) from our clinical center. The results demonstrated that $\mathrm{BCL} 11 \mathrm{~B}$ is significantly down-regulated in MDS patients as compared with healthy individuals (HIs). Importantly, lower BCL11B expression was found in MDS patients who were of high/very high risk, older than $60 \mathrm{y}$, or male and patients with SAML. Furthermore, low BCL11B expression appeared to be associated with poor overall survival (OS) for MDS patients, though the data were not yet significant enough at this point. In addition, BCL11B low-expressing MDS patients had shorter restricted mean survival time (RMST) than those with high BCL11B expression. Interestingly, BCL11B positively correlated with naive and activated memory CD4 $+\mathrm{T}$ cells, CD8 + T cells, and the $T$ cell receptor complex genes CD3E and CD3G, but it negatively correlated with regulatory $T$ cells (Treg). Additionally, co-occurrence of low BCL11B expression and CD3E and CD3G was associated with poor OS and shorter RMST. In conclusion, lower BCL11B expression in BM samples of MDS patients was associated with adverse clinical outcome.
\end{abstract}

Keywords: BCL11B, prognosis, myelodysplastic syndrome, immune cell

\footnotetext{
*Correspondence: wengjianyu1969@163.com; miyadu@hotmail.com; yangqiuli@hotmail.com

${ }^{+}$Xin Huang, Cunte Chen and Mengjun Zhong contributed equally to this work.

'Department of Hematology, Guangdong Provincial People's Hospital, Guangdong Academy of Medical Sciences, 510080 Guangzhou, PR China ${ }^{2}$ Key Laboratory for Regenerative Medicine of Ministry of Education, Institute of Hematology, Jinan University, 510632 Guangzhou, PR China
}

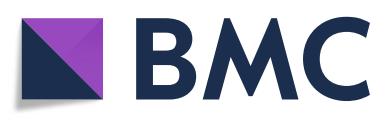

(c) The Author(s). 2021 Open Access This article is licensed under a Creative Commons Attribution 4.0 International License, which permits use, sharing, adaptation, distribution and reproduction in any medium or format, as long as you give appropriate credit to the original author(s) and the source, provide a link to the Creative Commons licence, and indicate if changes were made. The images or other third party material in this article are included in the article's Creative Commons. licence, unless indicated otherwise in a credit line to the material. If material is not included in the article's Creative Commons licence and your intended use is not permitted by statutory regulation or exceeds the permitted use, you will need to obtain permission directly from the copyright holder. To view a copy of this licence, visit http://creativecommons.org/licenses/by/4.0/ The Creative Commons Public Domain Dedication waiver (http://creativecommons.org/publicdomain/zero/1.0/) applies to the data made available in this article, unless otherwise stated in a credit line to the data. 
To the Editor,

Myelodysplastic syndrome (MDS) is an aggressive hematological disorder that displays hematologic and prognostic heterogeneity, illustrating the need for accurate mechanisms, prognostic biomarkers, and individualized therapies [1-3]. MDS progression appears to be associated with changes in the immune microenvironment that inhibit effective anti-tumor responses [4]. Anti-tumor effector $\mathrm{T}$ cells could be identified in the peripheral blood and BM of MDS patients, and this is considered to be favorable for clinical outcome; however, their mechanisms involved in promoting anti-tumor immunity have not been fully investigated [5-7]. B-cell leukemia/lymphoma 11B (BCL11B) plays an important role in regulating the development and maintenance of $\mathrm{T}$ cell activation [8]. Lower expression of BCL11B results in $\mathrm{T}$ cell dysfunction and is a reason for $\mathrm{T}$ cell deficiency in leukemia [9]. However, little is known about the impact of BCL11B expression on the prognosis of MDS patients. In this study, two large datasets containing transcriptome sequencing data from 270 MDS patients and 73 healthy individuals (HIs) from the Gene Expression Omnibus (GEO) database [10], and 31 bone marrow (BM) samples of MDS and 6 BM samples of patients with MDS progress to secondary acute myeloid leukemia (sAML) from our clinical center (Table S1) were used to explore the prognostic value of BCL11B and $\mathrm{T}$ cell activity for MDS patients.

In this study, the gene expression levels of BM samples from our clinical center were confirmed by quantitative real-time PCR, and the primers were listed in Table S2. We first found that BCL11B was significantly down-

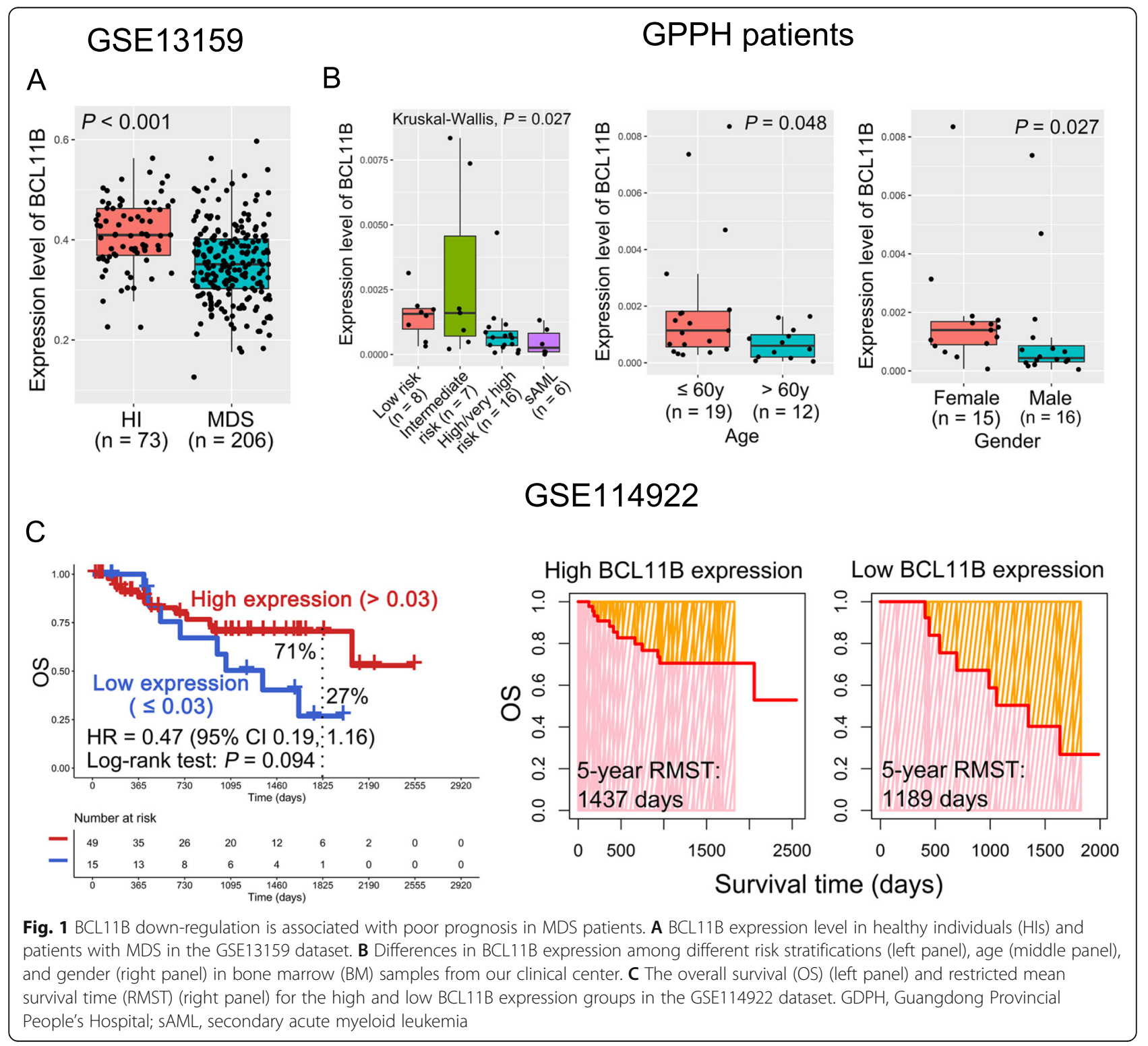




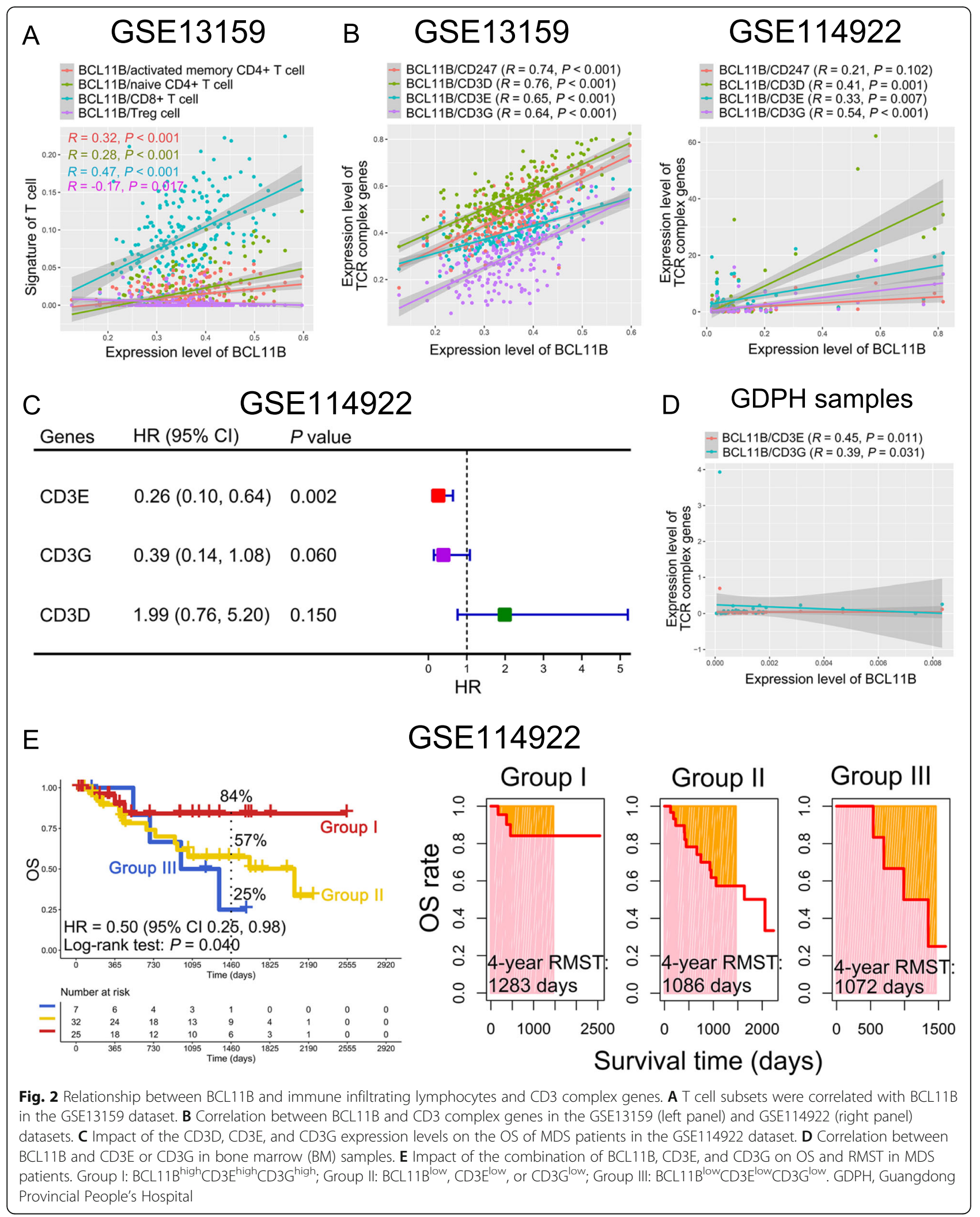


regulated in MDS patients compared with HIs in the GSE13159 dataset $(P<0.001$; Fig. 1 A). It is known that males, elderly age, and high-risk MDS patients have poor prognoses $[1,11]$. Notably, MDS patients with high/very high risk $(n=16)$ and patients with sAML $(n=6)$ had lower BCL11B expression than those with low- $(n=8)$ and intermediate-risk $(n=7)$ MDS patients in the BM samples $(P=0.027$; Fig. $1 B)$. Moreover, compared with patients who were younger than $60 \mathrm{y}$, those older than $60 \mathrm{y}$ had lower BCL11B expression $(P=0.048$; Fig. $1 \mathrm{~B})$. In addition, down-regulation of BCL11B was found in male patients as compared with female patients $(P=$ 0.027; Fig. 1B). Importantly, low BCL11B expression appeared to be correlated with poor overall survival (OS) for MDS patients in the GSE114922 dataset (5-year OS rate: $27 \%$ vs. $71 \%, P=0.094$; Fig. $1 \mathrm{C}$ and $\mathrm{S} 1 \mathrm{~A}$ ), though the data were not yet significant enough at this point. Furthermore, patients with low BCL11B expression had shorter restricted mean survival time (RMST) than those with high BCL11B expression (5-year RMST: 1,189 vs. 1, 437 days; Fig. 1 C). These results indicate that downregulation of BCL11B may play an important role in the progression of MDS.

To elucidate differences in BCL11B expression in different $\mathrm{T}$ cell subsets that primarily serve a regulatory role, we analyzed the correlation between BCL11B and T cell subsets. The results demonstrated that BCL11B mainly had a positive correlation with naive and activated memory CD $4+$ and CD $8+\mathrm{T}$ cells $(\mathrm{R}>0, P<0.001)$, and it had a negative correlation with Tregs in the GSE13159 dataset $(R=-0.17, P=0.017$; Fig. $2 \mathrm{~A})$. Interestingly, BCL11Brelated genes were enriched in the $\mathrm{T}$ cell receptor signaling pathway in the GSE13159 dataset $(P=0.047$, Fig. S2). Moreover, BCL11B was positively correlated with the T cell receptor (TCR) complex genes CD3D, CD3E, and CD3G in both the GSE13159 and GSE114922 datasets $(\mathrm{R}>0, P<0.01$; Fig. 2B). Notably, high expression of CD3E and CD3G appeared to be associated with favorable OS for MDS patients in the GSE114922 dataset $(P<0.1$; Fig. $2 \mathrm{C}$ and S1B-D), though the data were not yet significant enough at this point. Moreover, the expression levels of BCL11B and CD3E or CD3G had a positive correlation ( $\mathrm{R}>0, P<0.05$; Fig. 2D). We then further analyzed the contribution of the co-expression patterns of BCL11B, CD3E, and CD3G for the OS of MDS [12, 13]. Significantly, MDS patients who were BCL11B ${ }^{\text {low }} \mathrm{CD} 3 \mathrm{E}^{\text {low }} \mathrm{CD} 3-$ $\mathrm{G}^{\text {low }}, \mathrm{BCL} 11 \mathrm{~B}^{\text {low }}, \mathrm{CD} 3 \mathrm{E}^{\text {low }}$, or CD3G $\mathrm{G}^{\text {low }}$ had a worse OS rate than those who were $\mathrm{BCL} 11 \mathrm{~B}^{\text {high }} \mathrm{CD} 3 \mathrm{E}^{\text {high }} \mathrm{CD} 3 \mathrm{G}^{\text {high }}$ (4-year OS rate: $25 \%$ vs. $57 \%$ vs. $84 \%, P=0.040$ ), and they also had a shorter RMST (4-year RMST: 1,072 vs. 1,086 vs. 1,283 days; Fig. 2E).

In conclusion, lower BCL11B expression in BM samples of MDS patients was associated with adverse clinical outcome.

\section{Abbreviations}

BCL11B: B-cell chronic lymphocytic leukemia/lymphoma 11B; BM: bone marrow; GEO: Gene Expression Omnibus; GDPH: Guangdong Provincial People's Hospital; HI: healthy individuals; MDS: myelodysplastic syndrome; OS: overall survival; RMST: restricted mean survival time; SAML: secondary acute myeloid leukemia

\section{Supplementary information}

The online version contains supplementary material available at https://doi. org/10.1186/s40364-021-00302-y.

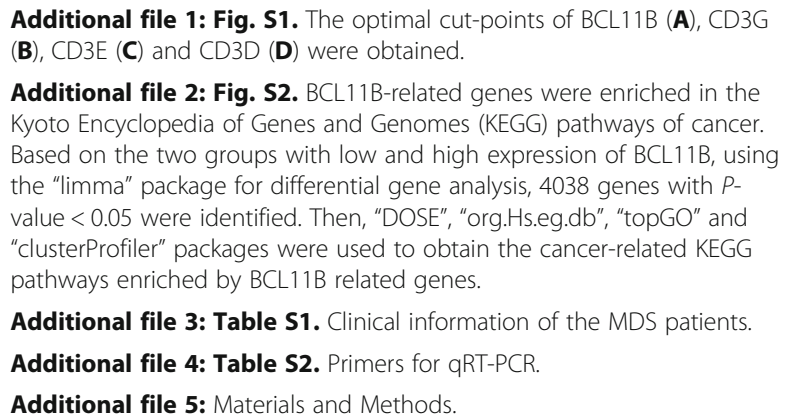

Additional file 2: Fig. S2. BCL11B-related genes were enriched in the Kyoto Encyclopedia of Genes and Genomes (KEGG) pathways of cancer. Based on the two groups with low and high expression of BCL11B, using the "limma" package for differential gene analysis, 4038 genes with $P$ value $<0.05$ were identified. Then, "DOSE", "org.Hs.eg.db", "topGO" and "clusterProfiler" packages were used to obtain the cancer-related KEGG pathways enriched by BCL11B related genes.

Additional file 3: Table S1. Clinical information of the MDS patients. Additional file 4: Table S2. Primers for $q R T-P C R$.

Additional file 5: Materials and Methods.

\section{Acknowledgements}

Not applicable.

\section{Authors' contributions}

$\mathrm{XH}, \mathrm{CTC}$, and MJZ performed the experiments, wrote the paper, and analyzed the data. YJZ helped to analyze the data. SXG and $L Z$ provided molecular and cytogenetic diagnoses. XD, XH, MML, CXD, PW, and ZSL diagnosed and treated the patients and provided clinical bone marrow samples. YQL, XD, and JYW designed the study and revised the manuscript. All authors read and approved the final manuscript.

\section{Funding}

This work was supported by grants from the intergovernmental International Cooperation on Scientific and Technological Innovation project of Chinese Ministry of Science and Technology (No. 2017YFE0131600), Guangdong Provincial Outstanding Young Medical Talents Supporting Research Foundation (No. KJ012019459), National Natural Science Foundation of China (No. 82070128), Guangdong Provincial Science and Technology Projects (No. 2017B020230004), and Guangdong Medical Science and Technology Research Fund Project (No. A2019525).

Availability of data and materials

Data available upon request.

\section{Declarations}

Ethics approval and consent to participate

This study was approved by the Ethics Committee of Guangdong Provincial People's Hospital. All participants provided written informed consent.

Consent for publication

Not applicable.

\section{Competing interest}

The authors declare that they have no competing interests.

Received: 3 March 2021 Accepted: 25 May 2021

Published online: 10 June 2021

\section{References}

1. Greenberg PL, Tuechler H, Schanz J, Sanz G, Garcia-Manero G, Solé F, Bennett JM, Bowen D, Fenaux P, Dreyfus F, et al. Revised international prognostic scoring system for myelodysplastic syndromes. Blood. 2012; 120(12):2454-65. 
2. Yu J, Li Y, Li T, Li Y, Xing H, Sun H, Sun L, Wan D, Liu Y, Xie X, et al. Gene mutational analysis by NGS and its clinical significance in patients with myelodysplastic syndrome and acute myeloid leukemia. Exp Hematol Oncol. 2020;9:2.

3. Gao S, Wang S, Song Y. Novel immunomodulatory drugs and neosubstrates. Biomark Res. 2020;8:2.

4. Montes P, Bernal M, Campo LN, González-Ramírez AR, Jiménez P, Garrido P, Jurado M, Garrido F, Ruiz-Cabello F, Hernández F. Tumor genetic alterations and features of the immune microenvironment drive myelodysplastic syndrome escape and progression. Cancer Immunol Immunother. 2019; 68(12):2015-27.

5. Glenthøj A, Ørskov AD, Hansen JW, Hadrup SR, O'Connell C, Grønbæk K. Immune Mechanisms in Myelodysplastic Syndrome. Int J Mol Sci. 2016;17(6): 944

6. Wang C, Yang Y, Gao S, Chen J, Yu J, Zhang H, Li M, Zhan X, Li W. Immune dysregulation in myelodysplastic syndrome: Clinical features, pathogenesis and therapeutic strategies. Crit Rev Oncol Hematol. 2018;122:123-32.

7. Geng S, Weng J, Du X, Lai P, Huang X, Chen S, Yang L, Li Y. Comparison of the distribution and clonal expansion features of the T-cell $\gamma \delta$ repertoire in myelodysplastic syndrome-RAEB and RAEB with progression to AML. DNA Cell Biol. 2012;31(10):1563-70.

8. Huang $X$, Du X, Li Y. The role of BCL11B in hematological malignancy. Exp Hematol Oncol. 2012;1(1):22.

9. Bartram I, Gökbuget N, Schlee C, Heesch S, Fransecky L, Schwartz S, Stuhlmann R, Schäfer-Eckhart K, Starck M, Reichle A, et al. Low expression of T-cell transcription factor BCL11b predicts inferior survival in adult standard risk T-cell acute lymphoblastic leukemia patients. J Hematol Oncol. 2014;7:51.

10. Huang R, Zhou L, Chi Y, Wu H, Shi L. LncRNA profile study reveals a sevenIncRNA signature predicts the prognosis of patients with colorectal cancer. Biomark Res. 2020;8:8.

11. Zeidan AM, Shallis RM, Wang R, Davidoff A, Ma X. Epidemiology of myelodysplastic syndromes: Why characterizing the beast is a prerequisite to taming it. Blood Rev. 2019;34:1-15.

12. Chen C, Xu L, Gao R, Wang S, Zhang Y, Wang C, Zeng C. Y L. Transcriptome-based co-expression of BRD4 and PD-1/PD-L1 predicts poor overall survival in patients with acute myeloid leukemia. Front Pharmacol. 2021;11:582955.

13. Chen C, Liang C, Wang S, Chio CL, Zhang Y, Zeng C, Chen S, Wang C, Li Y Expression patterns of immune checkpoints in acute myeloid leukemia. J Hematol Oncol. 2020;13(1):28

\section{Publisher's Note}

Springer Nature remains neutral with regard to jurisdictional claims in published maps and institutional affiliations.

Ready to submit your research? Choose BMC and benefit from:

- fast, convenient online submission

- thorough peer review by experienced researchers in your field

- rapid publication on acceptance

- support for research data, including large and complex data types

- gold Open Access which fosters wider collaboration and increased citations

- maximum visibility for your research: over $100 \mathrm{M}$ website views per year

At $\mathrm{BMC}$, research is always in progress.

Learn more biomedcentral.com/submissions 